\title{
THE USE OF WATERFALL MODEL IN APPLICATION DESIGN WEB-BASED MARYAM DEPARTMENT STORE
}

\author{
Indarti $^{1}$, Dewi Laraswati ${ }^{2}$, Adi Supriyatna ${ }^{3}$ \\ ${ }^{1}$ Sistem Informasi, Universitas Bina Sarana Informatika \\ ${ }^{2}$ Teknologi Komputer, Universitas Bina Sarana Informatika \\ ${ }^{3}$ Sistem Informasi Akuntansi, Universitas Bina Sarana Informatika \\ Jl. Kramat Raya No.98, Senen, Jakarta Pusat
}

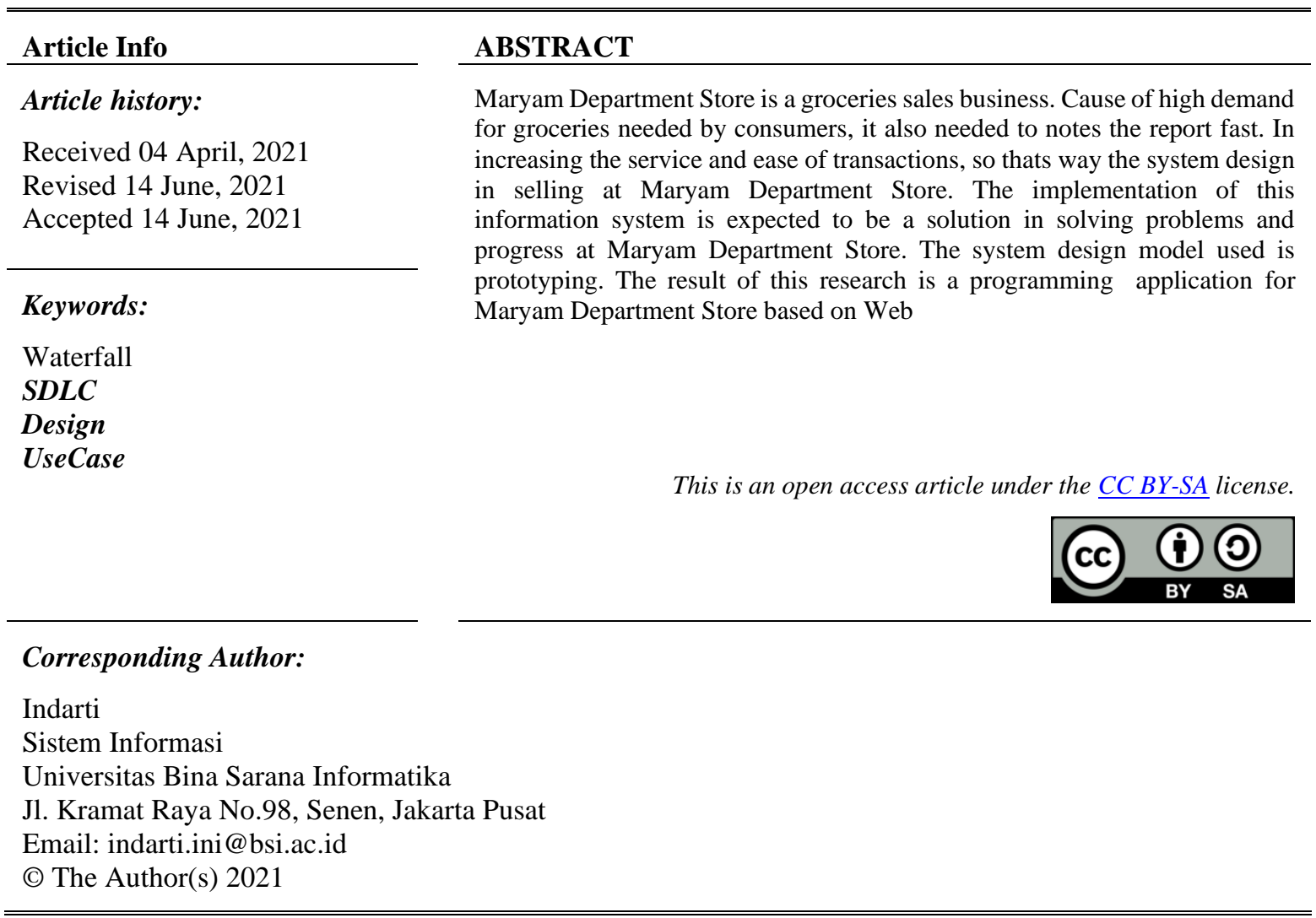

\section{Introduction}

The development of computer has a lot of benefits and advantages, because the sophistication of computer make everything fast process. The use of computerization is efficient in various aspects of life, there are business, education or government. It can increase productivity in time and up-to-date.Computers and cell phones are used in supporting internet to search, process and obtain information on variety of applications [1].

According to [2] in Hendry Jaya, "Sales are activities carried out by seller in selling goods or services to earn a profit from these transactions or transfering the goods and services from seller to buyer. Many businesses use internet to operate the company activities both in marketing or selling process [3] it called e-marketing. Emarketing able to expand the market network and able to make customers easier to find the product information and transaction online.

Sales transactions at Maryam Department Store still manually, it has not been computerized so it requires accuracy in big transaction in managing data [4]. On the other hand, a computerized system makes the information received about the stock of goods easily and quickly [5]. 
Website-based sales information system facilitate easy transactions and information received by customers quickly and real time [6]. A web-based computerized system is be able to accommodate customer needs in searching, able to give ease ordered process supporting the professionalism of all employees and data processing automaticly [7]

The department store sales application program includes incoming goods transactions, stock goods, and outgoing goods transactions to customers. This applications included in the point of sale application and can be applied in department stores or store warehouses.

With the existing problems to be more optimally, the management of goods sales at stores through website includes admin pages, it contain Master Data Suppliers, Goods, Units, Stocks, Users, Sales Transactions and report.

Table 1.

Literature Research

\begin{tabular}{|c|c|c|c|}
\hline Author & Research Problem & Methods & Result of the Research \\
\hline $\begin{array}{l}\text { Frieyadie, Ummi } \\
\text { Fatayat }\end{array}$ & $\begin{array}{l}\text { The process of ordering } \\
\text { and selling cosmetics is } \\
\text { still manually by using } \\
\text { telephone or coming } \\
\text { directly to the shop then it } \\
\text { will be recorded in the } \\
\text { order book so that it is } \\
\text { possible for errors record }\end{array}$ & Waterfall & $\begin{array}{l}\text { Mobile applications using the } \\
\text { Android platform with } \\
\text { Augmented Reality } \\
\text { technology and be able to } \\
\text { display brochures in an } \\
\text { attractive and realtime manner. }\end{array}$ \\
\hline $\begin{array}{l}\text { Ratih } \\
\text { Wahyuningrum }\end{array}$ & $\begin{array}{l}\text { To find out the reason of } \\
\text { interest and un-interest in } \\
\text { online buying towards e- } \\
\text { commerce website and to } \\
\text { analyze e-marketing } \\
\text { strategies to increase } \\
\text { people's online buying } \\
\text { interest in fashion } \\
\text { products. }\end{array}$ & $\begin{array}{l}\text { Qualitative and } \\
\text { quantitative research } \\
\text { methods } \\
\text { with a descriptive } \\
\text { approach }\end{array}$ & $\begin{array}{l}\text { Analisis dan perancangan strategi } \\
\text { e-marketing sebuah perusahaan } \\
\text { pada produk fashion sangat } \\
\text { diperlukan untuk mengetahui titik } \\
\text { kekuatan dan kelemahan } \\
\text { competitor demi meningkatkan } \\
\text { omzet perusahaan } \\
\text { Analyse and design of a } \\
\text { company's e-marketing } \\
\text { strategy on fashion products is } \\
\text { needed to determine the } \\
\text { strengths and weaknesses of } \\
\text { competitors in to increase } \\
\text { company's omzet. }\end{array}$ \\
\hline $\begin{array}{l}\text { Amelia, Joni } \\
\text { Devitra }\end{array}$ & $\begin{array}{l}\text { Inventory data } \\
\text { management is still } \\
\text { manually }\end{array}$ & Prototype & $\begin{array}{l}\text { Inventory management } \\
\text { information system prototype } \\
\text { at Advan Service Center Jambi }\end{array}$ \\
\hline $\begin{array}{l}\text { Dewi Laraswati, } \\
\text { Marlina }\end{array}$ & $\begin{array}{l}\text { Information is still limited } \\
\text { and conventionally, the } \\
\text { ordering process is not } \\
\text { flexible and data } \\
\text { processing is not } \\
\text { automated }\end{array}$ & Waterfall & $\begin{array}{l}\text { Produce a web-based wedding } \\
\text { package information system to } \\
\text { accommodate customer needs } \\
\text { in finding wedding or catering } \\
\text { information }\end{array}$ \\
\hline Dewi Laraswati & $\begin{array}{l}\text { The sales system is still } \\
\text { manually or there is no } \\
\text { automation process in } \\
\text { processing sales data for } \\
\text { heavy tools at PT. HKP. } \\
\text { The factors of main } \\
\text { problem include data, }\end{array}$ & Waterfall & $\begin{array}{l}\text { Sales information system } \\
\text { design is expected to solve the } \\
\text { existing problems at PT.HKP }\end{array}$ \\
\hline
\end{tabular}


documents, methods and

human resources

\section{Research Method}

This research used case study method by conduct the investigation at Maryam Department Store and several similar stores, especially in sales sector, until the existing problems are found. The system development model used is the waterfall model. The steps of this model are divided into five steps:

a) System Requirements Analysis

At this step, system requirements analysis is the first step to collect data, problem identification, problem solving suggestions, and system requirements analysis focused on making an application.

b) Design

Design is the step where design is provided into the expected design by using UML, Entity Relational Diagram (ERD).

c) Code Generation

In this step, the application of the design results is implemented into a program computer system by using OOP programming (object-based orientation).

d) Testing

In testing step, the program must be tested and focused on ensuring that all existing commands have been tested and external functions by using black box testing.

e) Support

Support is maintenance of data in applications regularly.

\section{Result and Discussion}

3.1. Software Requirements Analysis

A. Phase of Analysis

The department store sales system is made on a web-based in cash. It consists of customer table, goods table, user table and sales transaction table. In running program, the cashier can use a media browser. The following is described the needs of the Department Store sales system:

1. Needs User Pages

A1. Users can login by entering email and password

A2. User can process User data

A3. Users can process goods data

A4.User can process Customer data

A5.User can process sales transaction data

B. Use Case Diagram

1. Use Case Diagram of Department Store Sales Information System

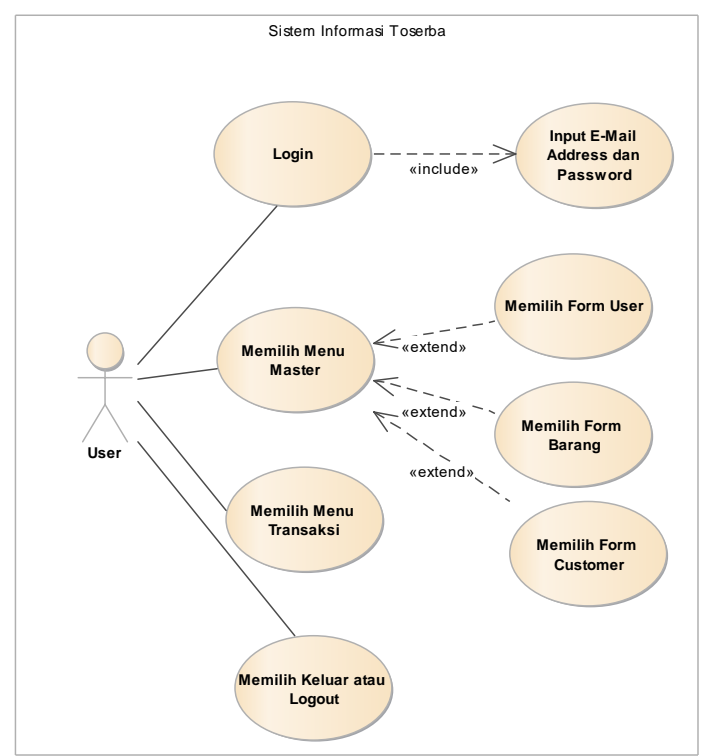

Figure 1. Use Case Information System of Toserba Maryam 
The use case diagram in the image above can be explained in the scenario table for use case login into the system:

Tabel 1

Description Use Case Page Login

\begin{tabular}{ll}
\hline Use Case Name & Login \\
\hline Requirements & A1 \\
\hline Goal & User can enter into Toserba Information System \\
\hline Pre-Conditions & User enters email and pasword \\
\hline Post-Conditions & User can access main menu \\
\hline Failed end Condition & User invalid to enter email or password \\
\hline Primary Actors & User \\
\hline Main Flow / Basic Path & 1. User enter email and password \\
& 2. System will make to email and password \\
& 3. It repeats if wrong input \\
\hline Invariant & 4. If valid, system will display main menu \\
\hline
\end{tabular}

\section{Activity Diagram}

Activity diagram describes the flow of a system, almost the same as flowcharts, but the difference is can support parallel behavior. The following is the activity diagram used in describing the flow of the Maryam Department Store system.

1. Activity Diagram Login Page

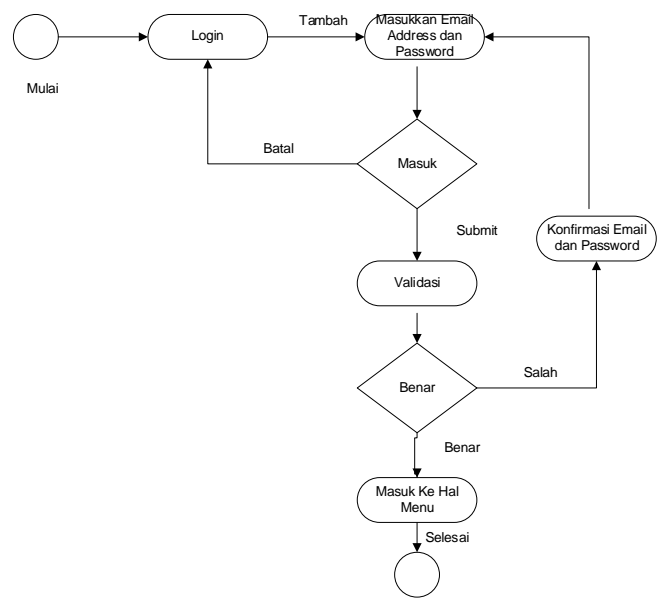

Figure 2 Activity diagram login.

In Figure 1 above illustrates a diagram of the activity of the user when loggin by entering their email and password.

D. Entity Relationship Diagram (ERD).

ERD is used to describe a data model from a database into a system. It consists of entities, attributes and relationships. The image below is an ERD model from the database used in Information System for Implementation in database design in sales system application at Maryam Department Store by using MySQL 


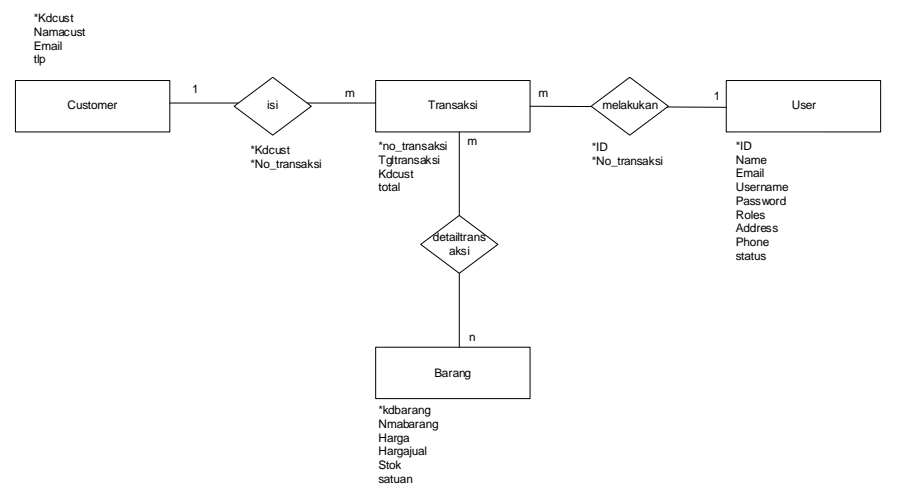

E. Logical Record Structure (LRS)

Figure 7 Model of ERD

In the Logical Record Structure image below shows the logic flow of a record in the system design.

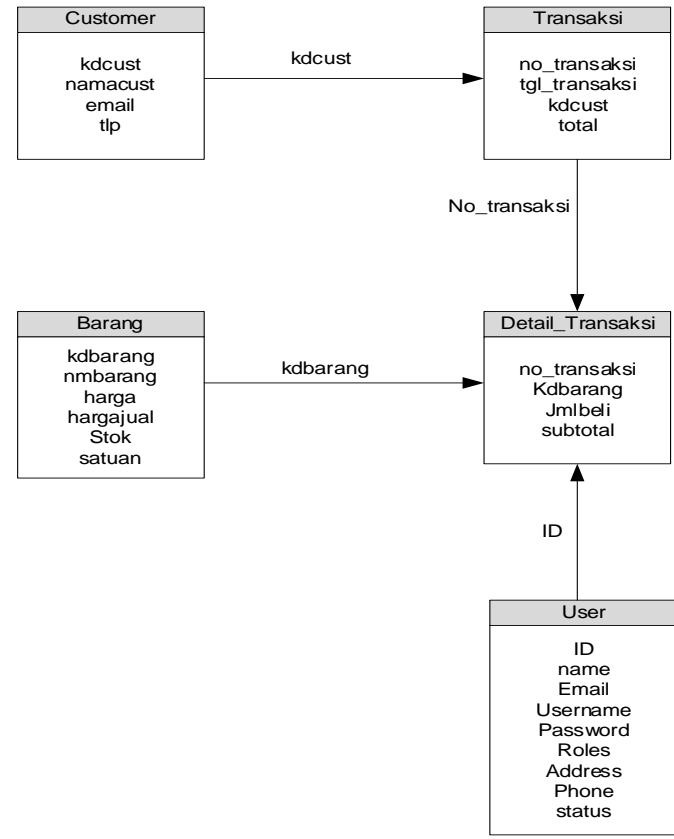

Figure 8. Logical Record Structure Model.

\section{Sequence Diagram}

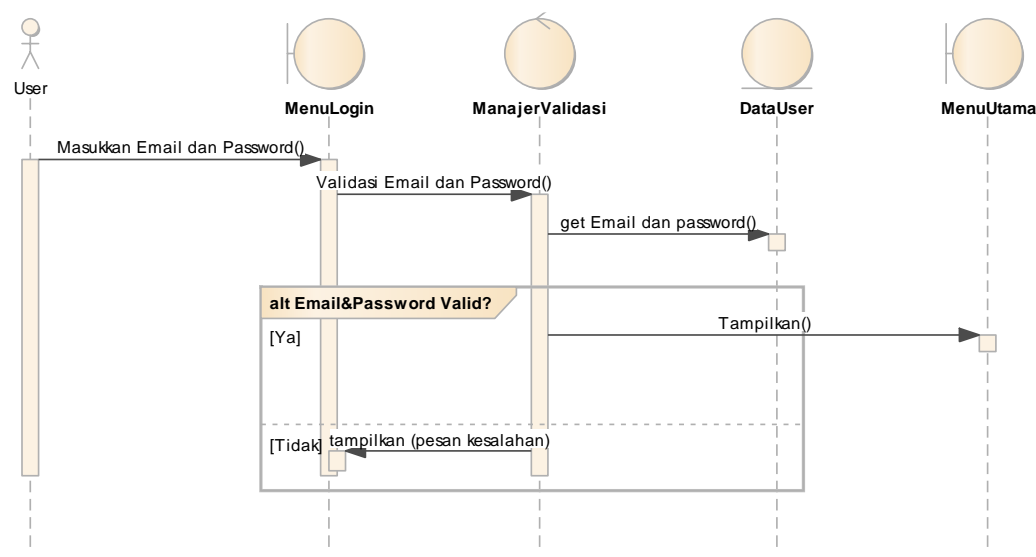

Figure 9. Sequence Diagram. 
In the picture above is a sequence diagram for the login menu. It describes the interaction between the user and objects in the system in the form of a message.

\section{Admin Interface}

1. Display Form Login User

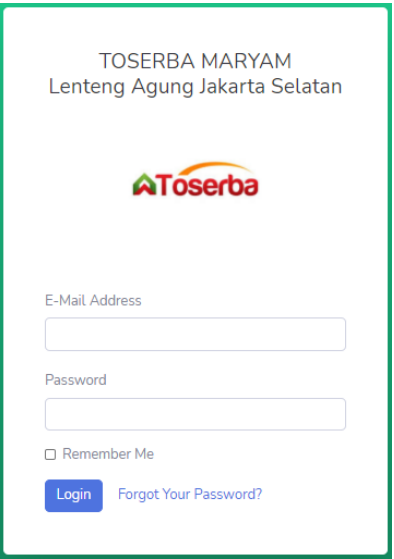

Figure 11. Display of Form Login User

2. Display Home User Admin

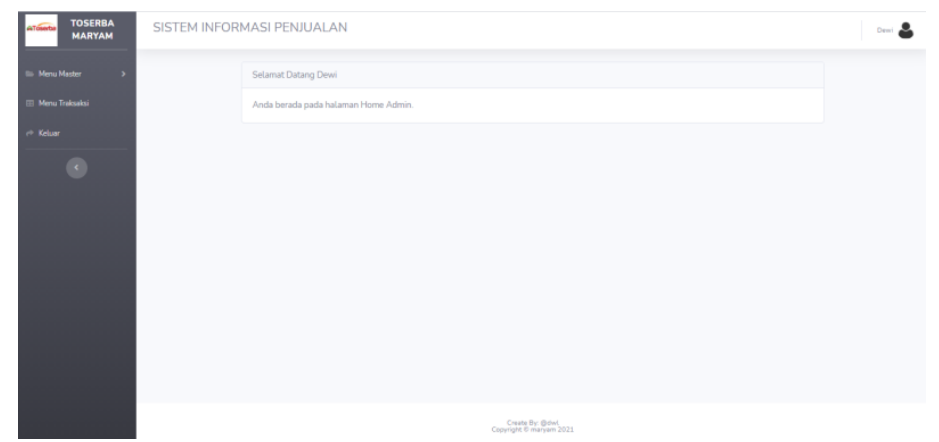

Figure 12. Display Home

3. Display Form User
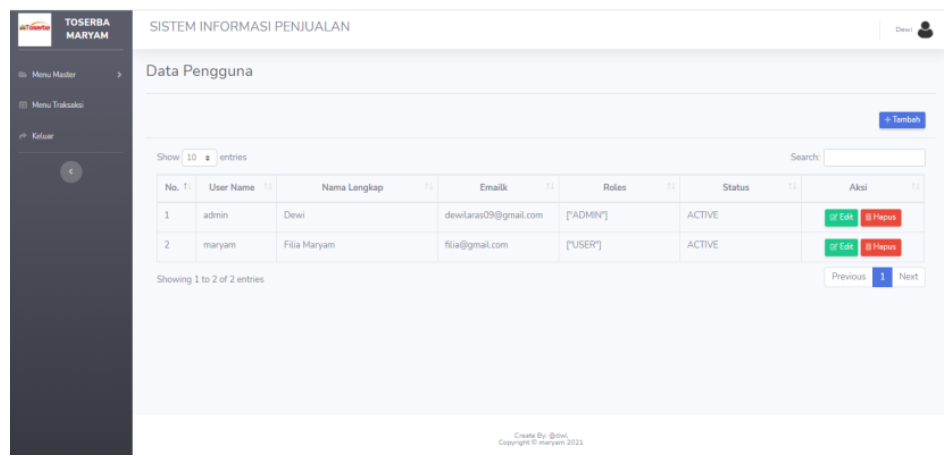

Figure 13. Display Form User

4. Display Page Customer Data 


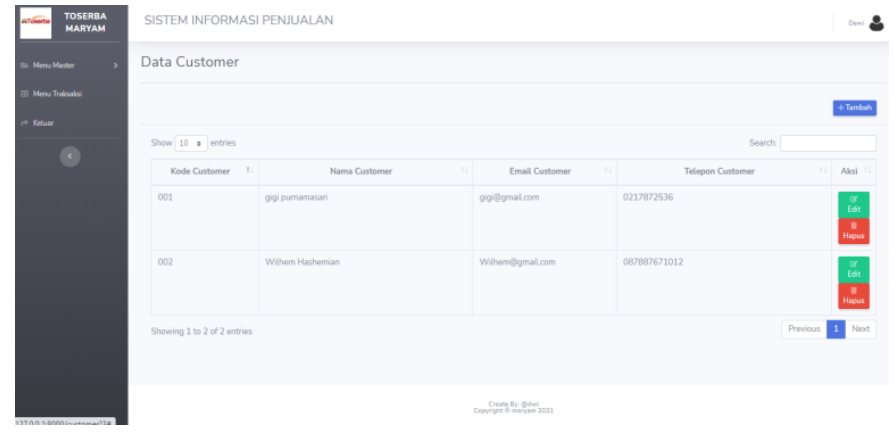

Figure 14 Display Page Customer Data

5. Display Page of Products Data

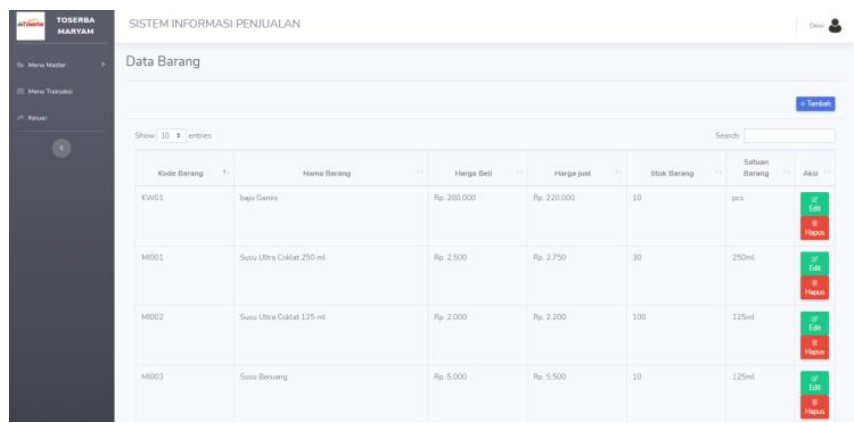

Figure 15 Display Halaman Form Barang

6. Display Page Menu of Selling Transaction
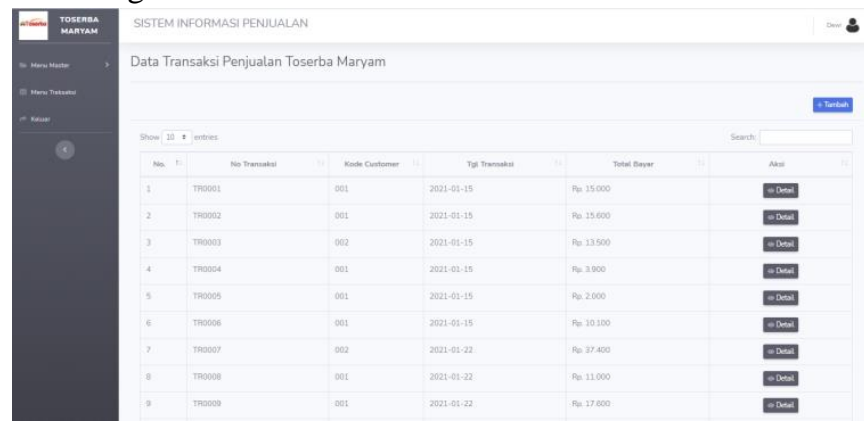

\subsection{Testing}

Figure 16 Display Page Transaction

Testing of programs is using blackbox testing focused on the process of program input and output.

A. Testing of the User Login Form.

Tabel 10

Testing Result of Black Box Testing Page Login User

\begin{tabular}{|c|c|c|c|c|c|}
\hline No. & Skenario Pengujian & Test Case & $\begin{array}{l}\text { Hasil yang } \\
\text { diharapkan }\end{array}$ & $\begin{array}{c}\text { Hasil } \\
\text { Pengujian }\end{array}$ & Kesimpulan \\
\hline 1. & $\begin{array}{l}\text { User Name dan } \\
\text { password tidak diisi } \\
\text { kemudian klik } \\
\text { tombol login }\end{array}$ & $\begin{array}{l}\text { Pelanggan } \\
\text { Name : } \\
\text { (kosong) } \\
\text { Password: } \\
\text { (kosong) }\end{array}$ & $\begin{array}{l}\text { Sistem akan } \\
\text { menolak akses } \\
\text { User dan } \\
\text { menampilkan } \\
\text { "Please fill Out } \\
\text { this field" }\end{array}$ & $\begin{array}{l}\text { Sesuai } \\
\text { Harapan }\end{array}$ & Valid \\
\hline
\end{tabular}




\begin{tabular}{|c|c|c|c|c|c|}
\hline 2. & $\begin{array}{l}\text { Mengetikkan User } \\
\text { Name dan password } \\
\text { tidak diisi atau } \\
\text { kosong kemudian } \\
\text { klik tombol login }\end{array}$ & $\begin{array}{l}\text { Pelanggan } \\
\text { Name: User } \\
\text { Password : } \\
\text { (kosong) }\end{array}$ & $\begin{array}{l}\text { Sistem akan } \\
\text { menolak akses } \\
\text { User dan } \\
\text { menampilkan } \\
\text { "Please fill Out } \\
\text { this field" }\end{array}$ & $\begin{array}{l}\text { Sesuai } \\
\text { Harapan }\end{array}$ & Valid \\
\hline 3. & $\begin{array}{l}\text { User Name tidak diisi } \\
\text { dan password diisi } \\
\text { kemudian klik } \\
\text { tombol login }\end{array}$ & $\begin{array}{l}\text { Pelanggan } \\
\text { Name: } \\
\text { (kosong) } \\
\text { Password: } \\
\text { password }\end{array}$ & $\begin{array}{l}\text { Sistem akan } \\
\text { menolak akses } \\
\text { User dan } \\
\text { menampilkan } \\
\text { "Please fill Out } \\
\text { this field" }\end{array}$ & $\begin{array}{l}\text { Sesuai } \\
\text { harapan }\end{array}$ & Valid \\
\hline 4. & $\begin{array}{l}\text { Mengetik User Name } \\
\text { dengan benar dan } \\
\text { Mengetikkan salah } \\
\text { satu kondisi salah } \\
\text { pada Password dan } \\
\text { kemudian klik tombol } \\
\text { login }\end{array}$ & $\begin{array}{l}\text { Pelanggan } \\
\text { Name: User } \\
\text { (benar) } \\
\text { Password: } 1 \\
\text { (salah) }\end{array}$ & $\begin{array}{l}\text { Sistem akan } \\
\text { menolak } \\
\text { akses Pelanggan } \\
\text { dan } \\
\text { menampilkan } \\
\text { "These } \\
\text { credentials do not } \\
\text { match our } \\
\text { records." }\end{array}$ & $\begin{array}{l}\text { Sesuai } \\
\text { Harapan }\end{array}$ & Valid \\
\hline 5. & $\begin{array}{l}\text { Mengetikkan User } \\
\text { Name dan password } \\
\text { dengan data yang } \\
\text { benar kemudian } \\
\text { klik tombol login }\end{array}$ & $\begin{array}{l}\text { Pelanggan } \\
\text { Name: User } \\
\text { (benar) } \\
\text { Password: } \\
\text { password } \\
\text { (benar) }\end{array}$ & $\begin{array}{l}\text { Sistem menerima } \\
\text { akses login dan } \\
\text { kemudian masuk } \\
\text { ke halaman utama } \\
\text { Sistem Informasi } \\
\text { Catering Wedding }\end{array}$ & $\begin{array}{l}\text { Sesuai } \\
\text { Harapan }\end{array}$ & Valid \\
\hline
\end{tabular}

B. Testing of the User Data Form

Tabel 11

Testing Result of Black Box Testing Page Data User

\begin{tabular}{|c|c|c|c|c|c|}
\hline No. & Skenario Pengujian & Test Case & $\begin{array}{l}\text { Hasil yang } \\
\text { diharapkan }\end{array}$ & $\begin{array}{c}\text { Hasil } \\
\text { Pengujian }\end{array}$ & Kesimpulan \\
\hline 1. & $\begin{array}{l}\text { Semua Textbox tidak } \\
\text { di isi. }\end{array}$ & $\begin{array}{l}\text { User Name, } \\
\text { Nama User, } \\
\text { Email, } \\
\text { Telpon, } \\
\text { Roles, } \\
\text { Alamat, } \\
\text { Status } \\
\text { Dikosongkan }\end{array}$ & $\begin{array}{l}\text { Sistem tidak } \\
\text { menyimpan data } \\
\text { User dan } \\
\text { menampilkan } \\
\text { pesan konfirmasi } \\
\text { "Please fill Out } \\
\text { this field" }\end{array}$ & $\begin{array}{l}\text { Sesuai } \\
\text { Harapan }\end{array}$ & Valid \\
\hline 2. & $\begin{array}{l}\text { Salah satu textbox } \\
\text { tidak diisi. }\end{array}$ & $\begin{array}{l}\text { User Name } \\
\text { Diisi, Nama } \\
\text { User, Email, } \\
\text { Telpon, } \\
\text { Roles, } \\
\text { Alamat, } \\
\text { Status } \\
\text { Dikosongkan }\end{array}$ & $\begin{array}{l}\text { Sistem tidak } \\
\text { menyimpan data } \\
\text { user dan } \\
\text { menampilkan } \\
\text { pesan konfirmasi } \\
\text { "Please fill Out } \\
\text { this field" }\end{array}$ & $\begin{array}{l}\text { Sesuai } \\
\text { Harapan }\end{array}$ & Valid \\
\hline
\end{tabular}




\begin{tabular}{|c|c|c|c|c|c|}
\hline 3. & $\begin{array}{l}\text { Semua textbox terisi } \\
\text { dengan lengkap }\end{array}$ & $\begin{array}{l}\text { User Name, } \\
\text { Nama User, } \\
\text { Email, } \\
\text { Telpon, } \\
\text { Roles, } \\
\text { Alamat, } \\
\text { Status Diisi } \\
\text { lengkap }\end{array}$ & $\begin{array}{l}\text { Sistem } \\
\text { menamplkan data } \\
\text { user yang } \\
\text { ditambahkan }\end{array}$ & $\begin{array}{l}\text { Sesuai } \\
\text { harapan }\end{array}$ & Valid \\
\hline
\end{tabular}

C. Testing of Customer Data Forms

Tabel 12

Testing Result of Black Box Testing Halaman Data Pelanggan

\begin{tabular}{|c|c|c|c|c|c|}
\hline No. & Skenario Pengujian & Test Case & $\begin{array}{l}\text { Hasil yang } \\
\text { diharapkan }\end{array}$ & $\begin{array}{c}\text { Hasil } \\
\text { Pengujian }\end{array}$ & Kesimpulan \\
\hline 1. & $\begin{array}{c}\text { Semua Textbox tidak } \\
\text { di isi. }\end{array}$ & $\begin{array}{c}\text { Kode } \\
\text { Pelanggan, } \\
\text { nama } \\
\text { Pelanggan, } \\
\text { Alamat, } \\
\text { Nomor } \\
\text { Telpon } \\
\text { Dikosongkan }\end{array}$ & $\begin{array}{c}\text { Sistem tidak } \\
\text { menyimpan data } \\
\text { Pelanggan dan } \\
\text { menampilkan } \\
\text { pesan konfirmasi } \\
\text { "Please fill Out } \\
\text { this field" }\end{array}$ & $\begin{array}{c}\text { Sesuai } \\
\text { Harapan }\end{array}$ & Valid \\
\hline 2. & $\begin{array}{l}\text { Salah satu textbox } \\
\text { tidak diisi. }\end{array}$ & $\begin{array}{c}\text { Kode } \\
\text { Pelanggan, } \\
\text { nama } \\
\text { Pelanggan, } \\
\text { Alamat Diisi, } \\
\text { Nomor } \\
\text { Telpon } \\
\text { Dikosongkan }\end{array}$ & $\begin{array}{l}\text { Sistem tidak } \\
\text { menyimpan data } \\
\text { Pelanggan dan } \\
\text { menampilkan } \\
\text { pesan konfirmasi } \\
\text { "Please fill Out } \\
\text { this field" }\end{array}$ & $\begin{array}{c}\text { Sesuai } \\
\text { Harapan }\end{array}$ & Valid \\
\hline 3. & $\begin{array}{l}\text { Semua textbox terisi } \\
\text { dengan lengkap }\end{array}$ & $\begin{array}{c}\text { Kode } \\
\text { Pelanggan, } \\
\text { nama } \\
\text { Pelanggan, } \\
\text { Alamat Diisi, } \\
\text { Nomor } \\
\text { Telpon } \\
\text { Dikosongkan }\end{array}$ & $\begin{array}{c}\text { Sistem } \\
\text { menamplkan data } \\
\text { Pelanggan yang } \\
\text { ditambahkan }\end{array}$ & $\begin{array}{c}\text { Sesuai } \\
\text { harapan }\end{array}$ & Valid \\
\hline
\end{tabular}

D. Testing of the Package Data Form

Tabel 12

Testing Result of Black Box Testing Page Package Data

\begin{tabular}{|c|c|c|c|c|c|}
\hline No. & Skenario Pengujian & Test Case & $\begin{array}{l}\text { Hasil yang } \\
\text { diharapkan }\end{array}$ & $\begin{array}{c}\text { Hasil } \\
\text { Pengujian }\end{array}$ & Kesimpulan \\
\hline 1. & $\begin{array}{c}\text { Semua Textbox tidak } \\
\text { di isi. }\end{array}$ & $\begin{array}{c}\text { Kode Paket, } \\
\text { Nama paket, } \\
\text { Harga, } \\
\text { Deskripsi } \\
\text { Dikosongkan }\end{array}$ & $\begin{array}{c}\text { Sistem tidak } \\
\text { menyimpan data } \\
\text { paket dan } \\
\text { menampilkan } \\
\text { pesan konfirmasi } \\
\text { "Please fill Out } \\
\text { this field" }\end{array}$ & $\begin{array}{c}\text { Sesuai } \\
\text { Harapan }\end{array}$ & Valid \\
\hline
\end{tabular}

Jurnal Teknologi dan Open Source, Vol. 4, No. 1, June 2021: 37 - 47 


\begin{tabular}{|c|c|c|c|c|c|}
\hline 2. & $\begin{array}{l}\text { Salah satu textbox } \\
\text { tidak diisi. }\end{array}$ & $\begin{array}{l}\text { Kode Paket, } \\
\text { Nama paket, } \\
\text { Harga Diisi, } \\
\text { Deskripsi } \\
\text { Dikosongkan }\end{array}$ & $\begin{array}{c}\text { Sistem tidak } \\
\text { menyimpan data } \\
\text { Pelanggan dan } \\
\text { menampilkan } \\
\text { pesan konfirmasi } \\
\text { "Please fill Out } \\
\text { this field" }\end{array}$ & $\begin{array}{c}\text { Sesuai } \\
\text { Harapan }\end{array}$ & Valid \\
\hline 3 & $\begin{array}{l}\text { Pengisian textbox } \\
\text { tidak sesuai tipe data }\end{array}$ & $\begin{array}{c}\text { Harga diisi } \\
\text { menggunaka } \\
\text { n huruf }\end{array}$ & $\begin{array}{c}\text { Sistem tidak bisa } \\
\text { menginput } \\
\text { textbox }\end{array}$ & $\begin{array}{l}\text { Sesuai } \\
\text { harapan }\end{array}$ & Valid \\
\hline 4. & $\begin{array}{l}\text { Semua textbox terisi } \\
\text { dengan lengkap }\end{array}$ & $\begin{array}{c}\text { Kode Paket, } \\
\text { Nama paket, } \\
\text { Harga, } \\
\text { Deskripsi } \\
\text { Diisi lengkap } \\
\text { sesuai tipe } \\
\text { data }\end{array}$ & $\begin{array}{c}\text { Sistem } \\
\text { menamplkan data } \\
\text { Pelanggan yang } \\
\text { ditambahkan }\end{array}$ & $\begin{array}{l}\text { Sesuai } \\
\text { harapan }\end{array}$ & Valid \\
\hline
\end{tabular}

E. Testing of the Cooking Menu Form

Tabel 13

Testing Result of Black Box Testing Form Menu Ordered

\begin{tabular}{|c|c|c|c|c|c|}
\hline No. & Skenario Pengujian & Test Case & $\begin{array}{l}\text { Hasil yang } \\
\text { diharapkan }\end{array}$ & $\begin{array}{c}\text { Hasil } \\
\text { Pengujian }\end{array}$ & Kesimpulan \\
\hline 1. & $\begin{array}{l}\text { Semua Textbox tidak } \\
\text { di isi. }\end{array}$ & $\begin{array}{l}\text { Pilih Paket, } \\
\text { Jumlah, } \\
\text { Pelanggan, } \\
\text { Tanggal } \\
\text { kirim, Uang } \\
\text { Muka, } \\
\text { dikosongkan }\end{array}$ & $\begin{array}{l}\text { Sistem tidak } \\
\text { menyimpan } \\
\text { pesanan dan } \\
\text { menampilkan } \\
\text { pesan konfirmasi } \\
\text { "Please fill Out } \\
\text { this field" }\end{array}$ & $\begin{array}{l}\text { Sesuai } \\
\text { Harapan }\end{array}$ & Valid \\
\hline 2. & $\begin{array}{l}\text { Salah satu textbox } \\
\text { tidak diisi. }\end{array}$ & $\begin{array}{l}\text { Pilih Paket, } \\
\text { Jumlah, } \\
\text { Pelanggan, } \\
\text { Tanggal } \\
\text { kirim Diisi, } \\
\text { Uang Muka } \\
\text { dikosongkan }\end{array}$ & $\begin{array}{l}\text { Pilih Paket, } \\
\text { Jumlah, } \\
\text { Pelanggan, } \\
\text { Tanggal kirim, } \\
\text { Uang Muka, } \\
\text { dikosongkan }\end{array}$ & $\begin{array}{l}\text { Sesuai } \\
\text { Harapan }\end{array}$ & Valid \\
\hline 3. & $\begin{array}{l}\text { Pengisian textbox } \\
\text { tidak sesuai tipe data }\end{array}$ & $\begin{array}{l}\text { Jumlah dan } \\
\text { Uang Muka } \\
\text { diisi } \\
\text { memakai } \\
\text { huruf }\end{array}$ & $\begin{array}{l}\text { Sistem tidak bisa } \\
\text { menginput textbox }\end{array}$ & $\begin{array}{l}\text { Sesuai } \\
\text { harapan }\end{array}$ & Valid \\
\hline 4. & $\begin{array}{l}\text { Semua textbox terisi } \\
\text { dengan lengkap dan } \\
\text { sesuai tipe data }\end{array}$ & $\begin{array}{l}\text { Pilih Paket, } \\
\text { Jumlah, } \\
\text { Pelanggan, } \\
\text { Tanggal } \\
\text { kirim Diisi, } \\
\text { Uang Muka } \\
\text { Diisi lengkap } \\
\text { sesuai tipe } \\
\text { data }\end{array}$ & $\begin{array}{l}\text { Sistem akan } \\
\text { menyimpan data } \\
\text { pesanan }\end{array}$ & $\begin{array}{l}\text { Sesuai } \\
\text { Harapan }\end{array}$ & Valid \\
\hline
\end{tabular}




\section{Conclusion}

The conclusions of this research are:

1. The running system is less effective and requires a long time in processing data on sales of goods at Maryam stores.

2. Sales data processing system designed consists of seven processes related the process of selling goods and the process of making reports.

3. The design of selling data process system of goods at Maryam store includes the design of input documents such as data on goods equipped with data dictionaries, output designs such as reports and printed report forms.

4. In the procedure for documenting the data, the data has not been carried out properly, so it's difficult to find the data.

5. Delay information in reports.

\section{Acknowledgement}

The researchers would like to thank to the owner of Maryam Department Store, especially Mrs. Filia Maryam, as the head of Maryam Department Store because for her support and permission the research conducted well

\section{References}

[1] L. Vinet and A. Zhedanov, "A 'missing' family of classical orthogonal polynomials," Journal of Physics A: Mathematical and Theoretical, vol. 44, no. 8, Jakarta, pp. 1689-1699, Apr. 2011.

[2] Mulyadi, “(Akuntansi, Ekonomi, Universitas Riau Kepulauan, Indonesia),” Measurement, vol. 12, no. 2, pp. 33-48, 2018, [Online]. Available:

https://www.neliti.com/id/publications/134744/penyusunan-strategi-dan-sistem-penjualan-dalamrangka-meningkatkan-penjualan-tok.

[3] Ratih Wahyuningrum, “Analisis Strategi E-Marketing untuk Meningkatkan Minat Beli Online," ESENSI J. Manag. Bisnis, vol. 21, no. 3, pp. 275-290, 2018.

[4] D. Laraswati, "Rancang Bangun Sistem Informasi Penjualan," Bianglala Inform., vol. 6, no. 2, pp. 21-25, 2018, [Online]. Available: https://ejournal.bsi.ac.id/ejurnal/index.php/Bianglala/article/view/5900.

[5] Amelia and J. Devitra, "Analisis dan Perancangan Sistem Informasi Manajemen Persediaan Barang pada Advan Service Center Jambi,” J. Manaj. Sist. Inf., vol. 3, no. 1, pp. 856-869, 2018, [Online]. Available: http://jurnalmsi.stikom-db.ac.id/index.php/jurnalmsi/article/view/138.

[6] Frieyadie and U. Fatayat, "Penggunaan Model Waterfall Dalam Perancangan Aplikasi Penjualan Kosmetik Berbasis Web," J. Ris. Inform., vol. 1, no. 4, pp. 159-166, 2019, [Online]. Available: http://ejournal.kresnamediapublisher.com/index.php/jri/article/view/84.

[7] D. Laraswati and M. Marlina, "Rancang Bangun Sistem Informasi pelayanan Paket Pernikahan Pada Mindo Wedding Organizer," Indones. J. Softw. Eng., vol. 5, no. 1, pp. 1-8, 2019, doi: 10.31294/ijse.v5i1.6177. 